\title{
IMPROVED PULP EVALUATIONS USING A COMBINATION OF FREE AND RESTRAINED DRYING OF HANDSHEETS
}

\author{
Charles Green ${ }^{\mathrm{a}}$ \\ Pulp evaluations traditionally use plate-dried handsheets. The evalu- \\ ation of pulp could be improved significantly by using side-by-side \\ comparison of handsheets that freely shrink when dried, in addition to \\ handsheets dried in the usual way.
}

Keywords: Pulp evaluations, Paper properties, Predictions, Drying restraint

Contact information: a: 23 Maryvale Drive, Webster NY 14580, techman@papercurl.com

Pulp properties traditionally have been evaluated with plate-dried handsheets. Changes (increases) in tensile strength have been reported often for a pulp or process. The question is, are these increases actually seen in paper? Quoting Setterholm and Chilson (1965), "It is apparent that a correlation between properties handsheets and machine made sheets will never be satisfactory if allowances are not made for effects due to variations in restraint during drying." The data in the figure illustrate the effect of restraint and free shrinkage on breaking length.

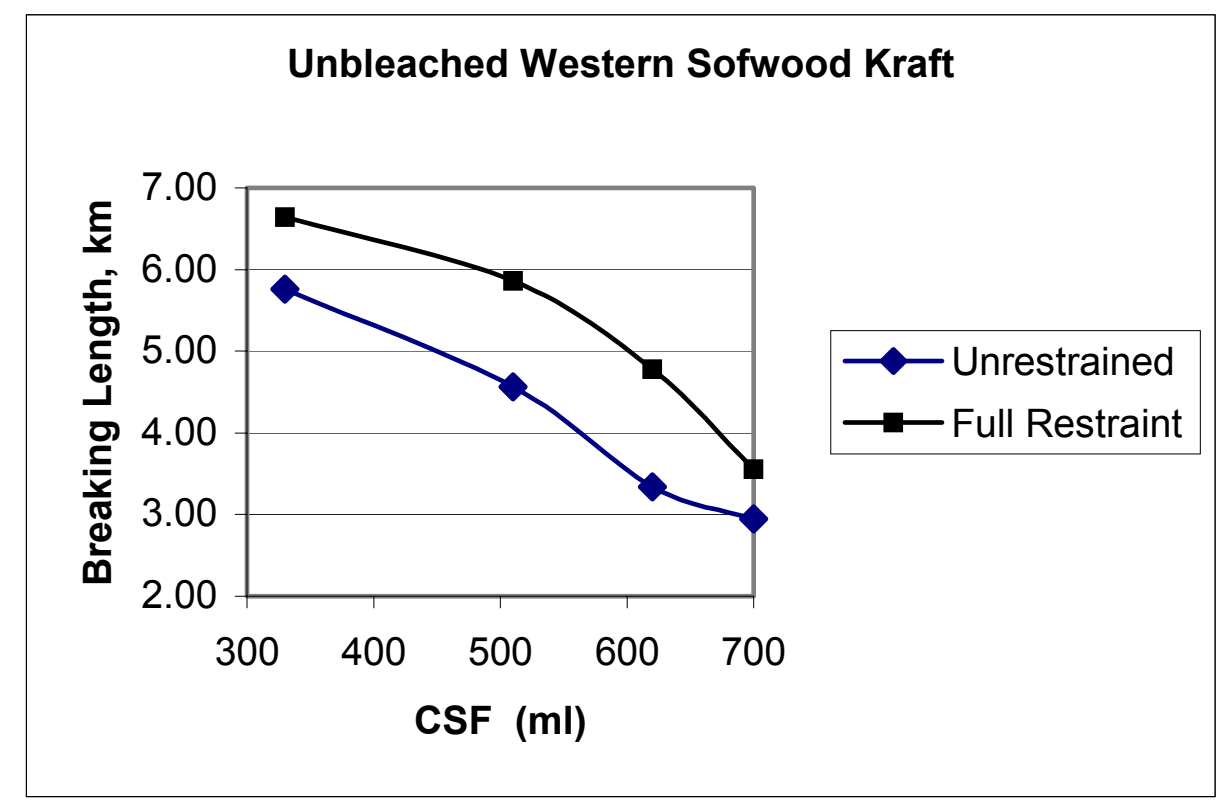

Recently a model that makes these allowances has been proposed. (Wahlström and Mäkelä 2005). The isotropic strength values of plate and freely dried handsheets are measured along with the amount of shrinkage. These are transformed into machine- and 
cross-directional properties in terms of sheet shrinkage using appropriate equations and data.

In recent times several researchers have been including the effect of drying shrinkage in their research on paper properties. On the other hand, literature articles on pulp evaluations continue to use only standard TAPPI handsheets. To improve the value of pulp evaluation data significantly the following is proposed for research and production:

1. Prepare and additional set of handsheets that are dried without restraint, measuring the shrinkage.

2. Measure the properties of both sets of sheets normally measured, plus modulus of elasticity.

3. Using methods such as those of Wahlström and Mäkelä (2005), and a nominal 2:1 property ratio, report machine-directional properties with no shrinkage and crossdirectional properties with 2 and 4 percent shrinkage.

This procedure should significantly increase the value of pulp evaluations and allow better application of information. The additional expense would well be justified.

\section{References}

Setterholm, V. C., and Chilson, W. A. (1965). "Drying restraint, its effect on the tensile properties of 15 different pulps," Tappi 48 (11), 634-640.

Wahlström, T., and Mäkelä, P. (2005). "Predictions of anisotropic multiply board properties based on isotropic ply properties and drying restraints," 13th Fund. Res. Symp., Cambridge. 